\title{
Effectiveness of the Multistage Jumping Rope Program in Enhancing the Physical Fitness Levels among University Students
}

\author{
Heildenberg C. Dimarucot ${ }^{1,2}$, Gil P. Soriano ${ }^{3, *}$ \\ ${ }^{1}$ Department of Human Kinetics, College of Arts and Sciences, San Beda University, Philippines \\ ${ }^{2}$ Graduate Studies and Transnational Education, Institute of Education, Far Eastern University, Manila, Philippines \\ ${ }^{3}$ College of Nursing, San Beda University, Philippines
}

Received August 14, 2020; Revised September 11, 2020; Accepted September 29, 2020

\section{Cite This Paper in the following Citation Styles}

(a): [1] Heildenberg C. Dimarucot, Gil P. Soriano, "Effectiveness of the Multistage Jumping Rope Program in Enhancing the Physical Fitness Levels among University Students," International Journal of Human Movement and Sports Sciences, Vol. 8, No. 5, pp. 235 - 239, 2020. DOI: 10.13189/saj.2020.080511.

(b): Heildenberg C. Dimarucot, Gil P. Soriano (2020). Effectiveness of the Multistage Jumping Rope Program in Enhancing the Physical Fitness Levels among University Students. International Journal of Human Movement and Sports Sciences, 8(5), 235 - 239. DOI: 10.13189/saj.2020.080511.

Copyright $\bigcirc 2020$ by authors, all rights reserved. Authors agree that this article remains permanently open access under the terms of the Creative Commons Attribution License 4.0 International License

\begin{abstract}
Several studies have shown that there has been a sudden decrease in physical activity levels among University students. This is alarming as physical inactivity is a known risk factor for many chronic diseases. Hence, Universities are in the best position to examine the personal and professional lifestyles among their students. The study was conducted in order to determine the effectiveness of the eight week multistage jumping rope training program in enhancing the physical fitness levels of Filipino university students. The study utilized a quasi-experimental research design and employed a purposive sample of 70 participants, who were screened using Physical Activity Readiness Questionnaire+ and were required to undergo a progressive eight-week jumping rope test. Cardiovascular endurance was assessed through volume of oxygen uptake or $\mathrm{VO}_{2}$ max before and after the multistage jumping rope training program. Data was analyzed using frequency, percentage, mean, standard deviation and paired t-test. The results revealed a significant difference in the $\mathrm{VO}_{2}$ max of males and females after the multistage jumping rope training program. The study affirms the effectiveness of the multistage jumping rope test in increasing the $\mathrm{VO}_{2}$ max of the participants. Hence, integrating the said program in the school curriculum can significantly enhance their cardiovascular fitness.
\end{abstract}

Keywords Cardiovascular Endurance, Physical
Fitness, Skipping Rope Test, University Students

\section{Introduction}

In recent years, the number of university students who have low physical fitness levels and observe unhealthy dietary patterns has increased dramatically [1]. Their physical activity behaviors are also affected by complex interaction of motivation and self-regulatory skills together with a distinct social and physical environment encompassing college life [2]. These includes increase academic workloads and substandard sporting facilities [3-4]

In the Philippines, studies have shown that Filipino youth have low physical activity and that they do not meet the recommended physical activity per week due to lack of time $[2,5]$. This is alarming as physical inactivity is a known risk factor of many chronic diseases [6]. Hence, promoting physical activity among university students is crucial in order to ensure that they develop regular physical activity patterns which they can extend throughout their adult life.

One of the important indicators of physical activity is cardiovascular (or cardiorespiratory, cardiopulmonary) 
endurance. It is defined as the "combined ability of the pulmonary system to promote gas exchange between the outside air and the circulating blood through the capillaries in the lungs, the cardiovascular system to transport oxygen to the working muscles, and the muscular system to utilize the oxygen [7]. Moreover, it also has mental health benefits along with other long-term effects like improved ability to extract oxygen from air during exercise, increased sweat rate, reduced risk of cancer, and increased density and breaking strength of bones, ligaments, and tendons, among many others. Thus, when one has an ideal cardiovascular endurance level, it would take less effort for that person to fulfill daily routine especially difficult tasks that require more physical exertion [8].

Despite the importance of having a high level of cardiovascular endurance, Macfarlane and Tomkinson [9] revealed that there has been a global decline in the cardiovascular endurance test performance of children and adolescents (6 to 19- year-olds) at a rate of $4-5 \%$ per decade since 1970. The performance of Asian children has declined at an average rate of $-0.44 \%$ per year since 1970 . Specifically, the Philippines were among the countries that performed the worst, below the overall Asian average [9]. Since then, there was no update on the Philippines' status as it was not included in the follow up study after 25 years. Thus, the current physical fitness status, specifically cardiovascular endurance, of Filipino university students in general is not yet known.

Studies have shown that rope-jump test was shown not only to have improved physical fitness status of an individual but can also their coordination, balance, agility, rhythm, speed. Further, constant performance of the said activity may increase static or dynamic muscular strength and may contribute to the development of motor skills [10, 11]. Hence, an eight-week training program was to develop in order to determine its effectiveness in increasing the cardiovascular endurance of the subjects by measuring the $\mathrm{VO}_{2} \max$

\section{Methods}

\subsection{Research Design}

The study utilized a quasi-experimental research design in order to determine the effectiveness of an eight-week jumping rope training program on the cardiovascular endurance of the subjects using the 1-Mile Walk Fitness Test [12].

\subsection{Research Participants}

The study involved male and female students and whose age ranged from 18 to 20 years old, and were also non-smokers and non-alcoholics. A total of 70 bonafide first year level students who were enrolled from physical fitness class (HKD-01) - a prerequisite of all physical education course subjects was recruited through purposive sampling. All the participants were required to have a physical examination under the supervision of the university doctor and passed all screening test under the Physical Activity Readiness Questionnaire+ (PAR-Q+ 2019) [13].

\subsection{Measurement and Instrumentation}

\subsubsection{The 1-Mile Walk Test}

A 1-mile walk test is a fitness assessment that measures an individual's level of cardiorespiratory fitness or is referred to as the maximal oxygen consumption which is constructed on the quantity of the time it takes someone to finish a mile of brisk walking. This fitness test is applicable to individuals who are unable to run for having a low fitness level or even injuries. It induces an exercise heart rate of at least 120 beats per minute (bpm) at the end of the fitness test [8]. Following the protocol of Hoeger, W. \& Hoeger, S. [12], a premeasured 1.0 mile course was selected where the test was conducted. Upon completing the 1-mile brisk walking, the participants were instructed to measure the time that it takes them to complete the course and to count their heart rate using the radial artery for 10 seconds and multiplied it by 6 to convert it to beats per minutes (bpm). In order to determine the time to walk, it was converted from a 00:00 value in order to allow for a numerical computation within the regression equation.

\subsubsection{Computation for $\mathrm{VO}_{2} \max$}

Table 1 shows the fitness level classification of $\mathrm{VO}_{2}$ max for Men and Women. The formula that was used to assess the cardiovascular endurance levels of the participants [12] is as follows:

Where: $\mathrm{VO}_{2} \max =\mathrm{ml} / \mathrm{kg} / \mathrm{min}$ $\mathrm{Wt}=$ Body weight in kilograms Age $=$ Age in years

Gender $(\mathrm{G})=$ Zero $(0)$ for females, One (1) for males *Time $(\mathrm{T})=$ Time to walk 1 mile $(00: 00)$ ${ }^{\wedge} \mathrm{HR}=$ Post Exercise Heart Rate (bpm)

$\mathrm{VO}_{2} \max =132.6-(0.17 \mathrm{x}$ weight in $\mathrm{kg})-(0.39 \mathrm{x}$ age $)$ $+(6.31 \mathrm{x}$ gender [0 for females; 1 for males] $)-(3.2 \times$ time to walk 1 mile $)$ - $(0.156 \mathrm{x}$ post-exercise heart rate $[\mathrm{bpm}])$.

\subsubsection{Multistage Jumping Rope Program}

Table 2 shows the multistage jumping rope program for eight weeks which was held in a school gym. It started with the usual warm-up exercise which is dynamic stretching for 10 minutes except for the first week with only 5 minutes. The jumping rope test that was done is progressive to which 100 repetitions are added per week which starts at 100 in Week One and ends in 800 in Week Eight. All tests ended with a 5-minute static stretching for cool down.

\subsubsection{Profile of the Participants}

The profile of the subjects was collected in the study which includes the age in years, sex, height in centimeters, weight in kilograms, and resting heart rate (bpm). 
Table 1. Fitness Level Classification for Men and Women

\begin{tabular}{|c|c|c|c|c|c|c|}
\hline \multicolumn{7}{|c|}{ Fitness Classification for Male } \\
\hline Age (year) & $\begin{array}{c}\text { Very Poor } \\
\text { (under) }\end{array}$ & Poor & Fair & Good & Excellent & $\begin{array}{c}\text { Superior } \\
\text { (over) }\end{array}$ \\
\hline $18-28$ & 37.9 & $38.0-41.0$ & $41.7-44.8$ & $45.6-48.5$ & $51.1-54.0$ & 55.5 \\
\hline \multicolumn{7}{|c|}{ Fitness Classification for Female } \\
\hline Age (year) & $\begin{array}{c}\text { Very Poor } \\
\text { (under) }\end{array}$ & Poor & Fair & Good & Excellent & $\begin{array}{c}\begin{array}{c}\text { Superior } \\
\text { (over) }\end{array} \\
\end{array}$ \\
\hline $18-28$ & $30.9-32.2$ & $32.3-35.2$ & $36.1-38.5$ & $39.5-42.4$ & 43.946 .8 & 49.6 \\
\hline
\end{tabular}

Source: Hoeger, W. \& Hoeger, S. (2016)

Table 2. Multistage Jumping Rope Program

\begin{tabular}{|c|c|c|c|c|}
\hline Week & $\begin{array}{c}\text { Intensity } \\
\text { (jumps/min) }\end{array}$ & $\begin{array}{c}\text { Warm up: } \\
\text { Dynamic Stretching } \\
\end{array}$ & Exercise & $\begin{array}{c}\text { Cool down: } \\
\text { Static Stretching }\end{array}$ \\
\hline 1 & 100 & 5 mins. & $\begin{array}{l}100 \text { repetitions per minute with } 30 \text {-second } \\
\text { rest }\end{array}$ & 5 mins. \\
\hline 2 & 200 & 10 mins. & $\begin{array}{l}200 \text { repetitions per minute with } 30 \text {-second } \\
\text { rest }\end{array}$ & 5 mins. \\
\hline 3 & 300 & 10 mins. & $\begin{array}{l}300 \text { repetitions per minute with } 30 \text {-second } \\
\text { rest }\end{array}$ & 5 mins. \\
\hline 4 & 400 & 10 mins. & $\begin{array}{l}400 \text { repetitions per minute with } 30 \text {-second } \\
\text { rest }\end{array}$ & 5 mins. \\
\hline 5 & 500 & 10 mins. & $\begin{array}{l}500 \text { repetitions per minute with } 30 \text {-second } \\
\text { rest }\end{array}$ & 5 mins. \\
\hline 6 & 600 & 10 mins. & $\begin{array}{l}600 \text { repetitions per minute with } 30 \text {-second } \\
\text { rest }\end{array}$ & 5 mins. \\
\hline 7 & 700 & 10 mins. & $\begin{array}{c}700 \text { repetitions per minute with } 30 \text {-second } \\
\text { rest }\end{array}$ & 5 mins. \\
\hline 8 & 800 & 10 mins. & $\begin{array}{l}800 \text { repetitions per minute with } 30 \text {-second } \\
\text { rest }\end{array}$ & 5 mins. \\
\hline
\end{tabular}

\subsection{Data Analysis}

The data collected was analyzed using the SPSS version 21.0 (IBM Corporation, Armonk, NY). Descriptive statistics such as frequency, percentage, mean and standard deviation were used for the profile of the subjects while paired t-test was used to determine the subjects' $\mathrm{VO}_{2}$ max before and after the multistage jumping rope program.

\section{Results}

Table 3 shows the profile of the subjects. It was revealed that the mean age of the participants was 18.27 $(\mathrm{SD}=0.61)$ while there were $37(52.86 \%)$ female and 33 (47.14\%) male participants. The mean height was 158.2 $(\mathrm{SD}=19.6)$, the mean weight was $72.12(\mathrm{SD}=38.09)$ while the mean resting heart rate $(\mathrm{bpm})$ was $69.79(\mathrm{SD}=16.95)$.

Table 3. Profile of the Participants $(n=70)$

\begin{tabular}{ccc}
\hline Profile & n (\%) & Mean (SD) \\
\hline Age (years) & & $18.27(0.61)$ \\
Sex: Male & $33(47.14)$ & \\
Female & $37(52.86)$ & \\
Height $(\mathbf{c m})$ & & $158.2(19.6)$ \\
Weight $(\mathbf{k g})$ & & $72.12(38.09)$ \\
Heart rate $(\mathbf{b p m})$ & & $(69.79(16.95)$ \\
\hline
\end{tabular}

On the other hand, Table 4 depicts the comparative analysis for the pre-test and post-test mean $\mathrm{VO}_{2}$ max of the subjects after undergoing the multistage jumping rope program. It was revealed that the pre-test $\mathrm{VO}_{2}$ max among males was very poor, with a mean score of $36.1(\mathrm{SD}=8.68)$ while the pre-test $\mathrm{VO}_{2}$ max among females was poor with a mean score of $32.53(\mathrm{SD}=3.90)$.

Focusing on the post-test result, it can be gleaned that the $\mathrm{VO}_{2}$ max among males became good with a mean score of $47.62(\mathrm{SD}=8.95)$ after the Multistage Jumping Rope Program. On the other hand, the post-test $\mathrm{VO}_{2}$ max among females was $37.34(\mathrm{SD}=3.71)$ which can be interpreted as fair.

The result of the paired t-test among males revealed a $t$ value of -8.756 and a computed p-value of 0.000 while among females the result yielded a $t$ value of -8.859 and p-value of $<0.05$.

\section{Discussion}

The objective of the study was to determine the effectiveness of the eight-week training program in increasing the cardiovascular endurance of the subjects by measuring the $\mathrm{VO}_{2}$ max among University students. Currently, there is limited research whether jump-rope based program can be used as a training method to 
improve the physical fitness among University students [14]. The main findings of the study revealed that the 8 -week training program significantly improves the cardiovascular endurance among the participants. Specifically, the $\mathrm{VO}_{2}$ max among males changed from very poor to good; while for females, it changed from poor to fair after undergoing the training program.

The study indicates that the Multistage Jumping Rope Program is an effective method for improving cardiovascular endurance among University students.

Table 4. $\mathrm{VO}_{2} \max$ Before and After the Multistage Jumping Rope Program $(\mathrm{n}=70)$

\begin{tabular}{ccccccc}
\hline \multirow{2}{*}{ Variables } & \multicolumn{2}{c}{ Pre-test } & \multicolumn{2}{c}{ Pos-test } & \multirow{2}{*}{ t-value } & p-value \\
& Mean & SD & Mean & SD & & \\
\hline $\begin{array}{c}\text { Male } \\
(\mathrm{n}=33)\end{array}$ & 36.1 & 8.68 & 47.62 & 8.95 & -8.756 & $* 0.000$ \\
$\begin{array}{c}\text { Female } \\
(\mathrm{n}=37)\end{array}$ & 32.53 & 3.90 & 37.34 & 3.71 & -8.859 & $* 0.000$ \\
\hline
\end{tabular}

$*$ p value is significant at 0.05 level

These findings are supported by the study of Partavi [14] who concluded that the 7-week rope jump training is and effective method for improving cardiovascular endurance among adolescent boys and Chao-Chien and Yi-Chun [15] who showed that the 12-week jumping rope training significantly influence the cardiovascular endurance among students who are intellectually impaired. Further, the study is consistent with previous literatures which reported that a rope-jump based training program significantly improves cardiovascular endurance $[14$, 16-19].

The findings of the study offered empirical evidence on the effectiveness of a jump-rope based program in enhancing the physical fitness among University students. Despite the positive findings of the study, there are some limitations that should be recognized. The study only included first year level students which was purposely selected and did not include other students, thereby limiting its generalizability. Also, other measures of physical fitness such as muscular strength and endurance, flexibility, agility, and speed were not included

\section{Conclusions}

The study affirms the effectiveness of the multistage jumping rope test in increasing the $\mathrm{VO}_{2}$ max of the subjects. The school administrators are advised to adapt the Multistage Jumping Rope Program to improve physical fitness among University students. It includes providing adequate infrastructure to support such activities and create awareness of such programs. Further, integrating a jump rope-based program in the curriculum and afterschool activities is recommended.

\section{REFERENCES}

[1] Agopyan A, "Comparison of body composition, cardiovascular fitness, eating and exercise habits among university students," Anthropologist vol. 19, no. 1, pp. 145-156, 2015.

[2] Acampado E., Valenzuela M. "Physical activity and dietary habits of Filipino college students: a cross-sectional study," Kinesiology vol. 50, pp. 57-67, 2018.

[3] Allender, S., Cowburn, G. \& Foster, C. "Understanding Participation in Sport and Physical Activity among Children and Adults: a review of qualitative studies. Health Education Research," vol. 21, no. 6, pp. 826-835, 2006

[4] Mchunu, S.J.A., "Reasons for Non-participation in Sports by Black learners at the Secondary School Level." Unpublished Master of Education Thesis. University of South Africa, 2008

[5] Cagas J., Torre B., Manalastas E, "Why do Filipinos exercise? Exploring motives from the perspective of Filipino youth," International Conference of Physical Education and Sports Science. Singapore, National Institute of Education, 2010

[6] Gutholh R., Stevens GA, Riley LM, Bull FC, "Worldwide trends in insufficient physical activity from 2001 to 2016: a pooled analysis of 358 population-based surveys with 1.9 million participants," Lancet Global Health, vol. 6, no. 10). e1077-e1086, 2018. DOI: 10.1016/S2214-109X(18)303577

[7] Manitoba Education, Citizenship and Youth, "Guidelines for fitness assessment in Manitoba Schools: A resource for Physical Education/Health Education," Manitoba: Minister of Education, Citizenship and Youth. (accessed July 17, 2020)

[8] Fahey T., Insel P., Roth W, "Fit \& well: Core concepts and labs in physical fitness and wellness" (12th ed.). New York: McGraw Hill, 2017.

[9] Macfarlane D., Tomkinson G, "Evolution and variability in fitness test performance of Asian children and adolescents. In Pediatric Fitness. Secular Trends and Geographic Variability by Tomkinson GR, Olds TS (eds): Med Sport Sci. Basel, Karger, 2007, 50, pp. 143-167, 2007.

[10] Brancazio P.J. "Sport Science: Physical Laws and Optimum Performance.” New York: Simon and Schuster; 1984.

[11] Chao-Chien, C., \& Yi-Chun, L., "Jumping Rope Intervention on Health-Related Physical Fitness İn Students with Intellectual Impairment." The Journal of Human Resource and Adult Learning, vol. 8, no.1, pp. 56-62, 2012

[12] Hoeger WK., Hoeger, SA, "Principles and labs for Fitness \& Wellness," (14th ed). USA: Wadsworth, Cengage Learning, 2016.

[13] Warburton DER, Jamnik VK, Bredin SSD, Gledhill N, "The Physical Activity Readiness Questionnaire for Everyone (PAR-Q+) and Electronic Physical Activity Readiness Medical Examination (ePARmed-X+)," Health \& Fitness Journal of Canada, vol. 4, no. 2, pp. 3-23, 2011

[14] Partavi S., "Effects of 7 weeks of rope-jump training on cardiovascular endurance, speed, agility in middle school 
student boys," Sport Science, vol. 6, no. 2, pp. 40-43, 2013.

[15] Chao-Chien C., Yi-Chun L, "Jumping Rope Intervention on Health-Related Physical Fitness in Students with Intellectual Impairment," The Journal of Human Resource and Adult Learning, vol. 8, no. 1, pp. 56-62, 2012.

[16] Yeh HC., "The role of vision in rope skipping training for balance development in the mental retardation," /Unpublished Master's Thesis/. Taipei: National Taiwan Normal University, 2007.

[17] Tsai YH, "Effect of rope jumping training on the health related physical fitness of students with amblyopia," /Unpublished Master's Thesis/. Taipei: National Taiwan Normal University, 2009.

[18] Chen HM., "The Effects of rope skipping on health-related physical fitness in student with mild intellectual disability: A case study,"/Unpublished Master's Thesis/. Taipei: National Taiwan Normal University, 2010.

[19] Jahromi MS., Gholami M., "The effect of jump-rope training on the physical fitness of 9-10 years old female students," Advances in Applied Science Research, vol. 6, no. 4, pp. 135-140, 2015. 